\title{
Strategy for research and development in the cave mining industry
}

\author{
GA Ferguson Seltrust Associates Limited, UK \\ D Cuello Newcrest Mining Limited, Australia \\ P Gandara Codelco, Chile \\ Y Potvin Australian Centre for Geomechanics, The University of Western Australia, Australia \\ E Rojas Codelco, Chile
}

\begin{abstract}
Some four decades ago, P Tregelles, Director of the Mining Research and Development, National Coal Board, Bretby, United Kingdom, outlined a strategy upon which research and development work could maximise its contribution to the safety and productivity of the coal mining industry in the United Kingdom. Such a strategy was founded upon the progress of projects through four phases: research, development, demonstration, and exploitation. Whilst it might be said that cave mining invariably provides safe and highly productive operations, it faces a number of considerable challenges in the areas of caving mechanics, rock mass blasting, ground support, measurement of in situ rock mass properties, modifying rock mass properties (preconditioning and de-stressing), and monitoring the response of the rock mass to the various phases of cave mining.

In a similar fashion to the approach of Tregelles, this paper suggests the concept of establishing a global cave mining research and development framework co-ordinated within an informal network, upon which the global cave mining industry might adopt a consensus with respect to the research and development required over the next two to three decades, to maximise safety and thereby improve productivity. Commencing with a discussion and definition of present and future cave mining problems, a global strategy may be structured upon the mines best placed to study and develop solutions to specific mining problems, acting as development centres - where advances can be shared and exchanged.
\end{abstract}

Keywords: autonomous mining, cave mining variant, mudrush, numerical modelling, preconditioning, $R \& D$

\section{Introduction}

Tregelles (1978) argued that the justification for research and development (R\&D) in the coal mining industry of the United Kingdom rested upon two conditions: first, that the industry had a significant future, and second, that $R \& D$ can contribute to improving that future. In actual fact, the history of underground coal mining in the United Kingdom was determined by the nature of the coal deposits - which tended to be faulted and of insufficient dimensions to promote high-productivity mechanised operations. Thus, underground coal mining in the United Kingdom could not compete with more favourable coal deposits worldwide, and today no longer exists.

Today, with the sustained rate of global growth over recent times, it may be said that the future of the base and precious metals mining industry is secure. However, the need for innovative progress in the industry is clear, and more metals must be produced with greater safety and efficiency with the goals of reducing costs and meeting global demand. Achieving these goals will largely depend upon the influence of:

- Management by its style and competence.

- Workforce, by its attitude and motivation.

- Engineers and scientists, by the progress that is made in the application of technology to solve the problems of the industry through applied and fundamental research projects. 


\section{Current and future cave mining problems}

Cave mining problems are experienced throughout the process of project design, project implementation, consequent mining operation, and final closure. Caving operations worldwide such as Cadia Valley Operations (Newcrest Mining), El Teniente (Codelco), Grasberg (Freeport-McMoRan), Kiruna (LKAB) and Palabora (Palabora Copper (Pty) Ltd) have all experienced difficulties brought about by mining activities. Given the size of the deposits extracted, these caving mines have had to learn to deal with unexpected problems, in particular when implementing extension in depth of operations.

It could be expected that brown-field projects would suffer fewer problems than green-field projects, but this is not always the case. Brown-field projects can have the benefit of decades of mining experience and evidence-based mining designs, but project development in the wrong hands and unexpected mining environments can have severe financial impacts. What chance then do green-field projects have, such as the Resolution and Wafi-Golpu projects, with respect to predicting, with certainty, how the planned mining operations will play out? Key to resolving the problem of predicting the success of caving operations in unknown mining environments, where corporations are asked to risk billions of dollars in funding, is adequately characterising the rock mass. Current industrial practice is simply inadequate in this respect, and operational and fundamental research in this area is warranted. Fortunately, experience from the oil industry is available to guide future development of rock mass characterisation from exploration programs, such as downhole microseismic monitoring (Maxwell et al. 2010).

There are many shared and distinct cave mining problems that are taking place in the world today (Table 1).

Table 1 Current and future cave mining problems

\begin{tabular}{|c|c|c|}
\hline Mine/future mine & Mining problems & Potential research approach \\
\hline Cadia East & $\begin{array}{l}\text { Seismicity (high draw height, } \\
\text { cave back progression) }\end{array}$ & Applied - short to medium-term \\
\hline Cadia East extension & $\begin{array}{l}\text { Seismicity (complex stress } \\
\text { fields/increasing rock mass } \\
\text { competency) }\end{array}$ & Applied - short to medium-term \\
\hline El Teniente & $\begin{array}{l}\text { Seismicity (complex stress } \\
\text { fields/increasing rock mass } \\
\text { competency) }\end{array}$ & $\begin{array}{l}\text { Research applied over two to three decades to } \\
\text { derive current solution }\end{array}$ \\
\hline Chuquicamata & Dilution & Applied - short to medium-term \\
\hline Grasberg & Seismicity, ground stability & Applied - short to medium-term \\
\hline \multirow[t]{3}{*}{ Resolution } & High temperatures & Applied - remote working practices - short-term \\
\hline & High field stresses & Applied - short to medium-term \\
\hline & Rock mass characterisation & \\
\hline \multirow[t]{3}{*}{ Wafi-Golpu } & High temperatures & Applied - remote working practices - short-term \\
\hline & High field stresses & Applied - short to medium-term \\
\hline & Rock mass characterisation & \\
\hline Shared/common & Airblast & Applied - short to medium-term \\
\hline Shared/common & Blasting mechanics & Applied/fundamental - short to long-term \\
\hline Shared/common & Dilution & Applied - short to medium-term \\
\hline Shared/common & Mudrush & Applied - remote working practices - short term \\
\hline
\end{tabular}


Research objectives need to focus upon how best to resolve key project and operational problems/risks and their impact upon critical performance indices, for example:

- Mine safety indices.

- Development metres advance per month.

- Load-haul-dumper (LHD) effective operating hours, tonnes per shift and tpd/ $/ \mathrm{m}^{2}$.

- Tonnes per manshift (total mine and contractor workforces).

- Mining cost per tonne (development and operating costs).

\section{Cave mining industry: global research and development framework}

Given the foregoing, the concept of establishing a global cave mining R\&D framework co-ordinated within an informal network arises first from the manner in which information is shared today almost instantaneously across the globe. Secondly, taken together with the mobility of engineers today, and historically, it is improbable that individual mining companies might be able to maintain advances for their sole financial benefit. A shared approach, therefore, makes sense from both commercial and mining industry health and safety aspects. Two alternatives present themselves for consideration: a Chamber of Cave Mining Research organisation, or strong internal research groups supported by universities with world class fundamental research. How to go about establishing the framework needs to take account of how cave mining R\&D work has taken place over the past two to three decades or so, and how successful it has been.

International Block Caving Study (ICS) projects have been carried out by the de facto Chamber of Mining Research, and it might be argued that despite the very substantial sums spent, the cave mining industry is very much where it was two decades ago. Another alternative is the Canadian Mining Industry Research Organization, which is an industry-based, not-for-profit, collaborative research organisation for Canada's industrial mining. However, this body may be thought of as another model which yielded limited success. An alternative approach that is seen as having been more successful is a return to strong industry internal research groups, such as Noranda Technology, Inco Research and Mount Isa Mining Research, which were among the most innovative and productive mining research organisations in the 1970s and 1980s. It is considered that the mining industry was fundamentally mistaken when it decided that research was not a core business and started to dismantle internal research facilities. Without doubt, the best caving research over the last couple of decades has arguably been achieved by Codelco, who have maintained a very strong internal research group with practical advances with respect to developing caving guidelines, ground support and rock mass preconditioning.

\section{$4 \quad$ Mining research and development strategy}

A strategy for mining R\&D has to take full account of the characteristics of the innovation process in the mining industry (Figure 1):

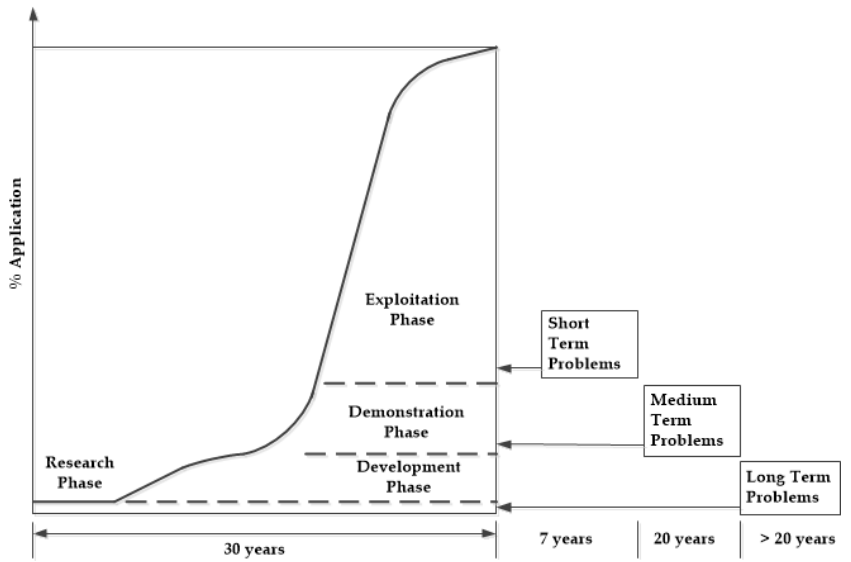

Figure $1 \quad$ R\&D strategy - the four phases of work (after Tregelles 1978) 
1. $R \& D$ is concerned with solving problems related to safety and productivity.

2. A dramatic improvement in productivity and safety in the industry is only made when a key problem of the industry is solved.

3. Solutions to major problems are not achieved at a stroke. Major advances are a consequence of a step-by-step progression that may take say 15 to 20 years (Landeros et al. 2012). Progressive advances have many advantages over a great leap forward:

a. The direction of a development can be modified in the light of experience.

b. Interim profits can be taken as steps are implemented.

c. Setbacks in development are not major upsets.

d. Management and the workforce become acquainted with new techniques and technologies, and training can be progressively introduced.

4. R\&D work changes as the solution progresses, in the:

a. Research phase which is concerned with, and seeks to understand, the problems that may confront the industry in 15-30 years' time, the nature of the natural phenomena of the mining environment and the relevance of progress in other fields and technologies.

b. Development phase, where the object is to provide solutions to the most likely problems of 5-10 years in the future, in which tests and solutions are tried using known mining industry technology, and then technologies from other industries.

c. Demonstration phase, to display the advantages to the workforce and management, assess training requirements and to improve reliability.

d. Finally, in the exploitation phase, solutions are shared with the industry at large, and mines implement the solutions; the speed of which depends upon how much involvement the industry has had during the previous three phases.

The principal areas of research are expected to encompass:

1. Rock mass characterisation and modification (preconditioning).

2. Field stress characterisation and management.

3. Rock mass excavation techniques.

4. Response of the rock mass to excavation techniques.

\section{$5 \quad$ Cave mining research worldwide: past and present}

\subsection{El Teniente: autonomous mining operations - demonstration, exploitation phases}

Cave mining-induced seismicity is a significant risk to miners and has led to the mitigation measure and strategic objective to exclude the workforce from high-risk areas. Consequently, a fundamental innovation direction within the El Teniente mine is automation of the mobile mining fleet, which removes operating personnel from areas where the risk is judged to be higher than normal. Automation of the mining fleet has been a strategic goal of El Teniente mine for more than two decades, which commenced in 1996, driven by the necessity to re-start the Sub- 6 mining sector, which had been stalled by mining-induced seismicity. This experience was followed by the implementation of the semi-autonomous LHD extraction of the Pipa Norte sector. At that time, the Sandvik AutoMine system was employed, utilising a fleet of three $13 \mathrm{yd}^{3}$ LHDs to produce 10,000 tpd. Drawpoint muck was loaded via teleoperation with the associated transportation and dumping activities performed in autonomous mode. Teleoperation of the Pipa Norte LHDs was performed from surface, with a single operator controlling more than one machine. However, despite good 
technological results, with a reduction in the exposure of personnel to the production environment, the installation failed to achieve the same productivities of manual LHD operations.

Consequently, El Teniente, which has a long history of seeking to implement innovative methods across its operations, adopted a strategy of awaiting the development of a more mature technology in mining mobile equipment that might be tested in the mine (Figure 2).

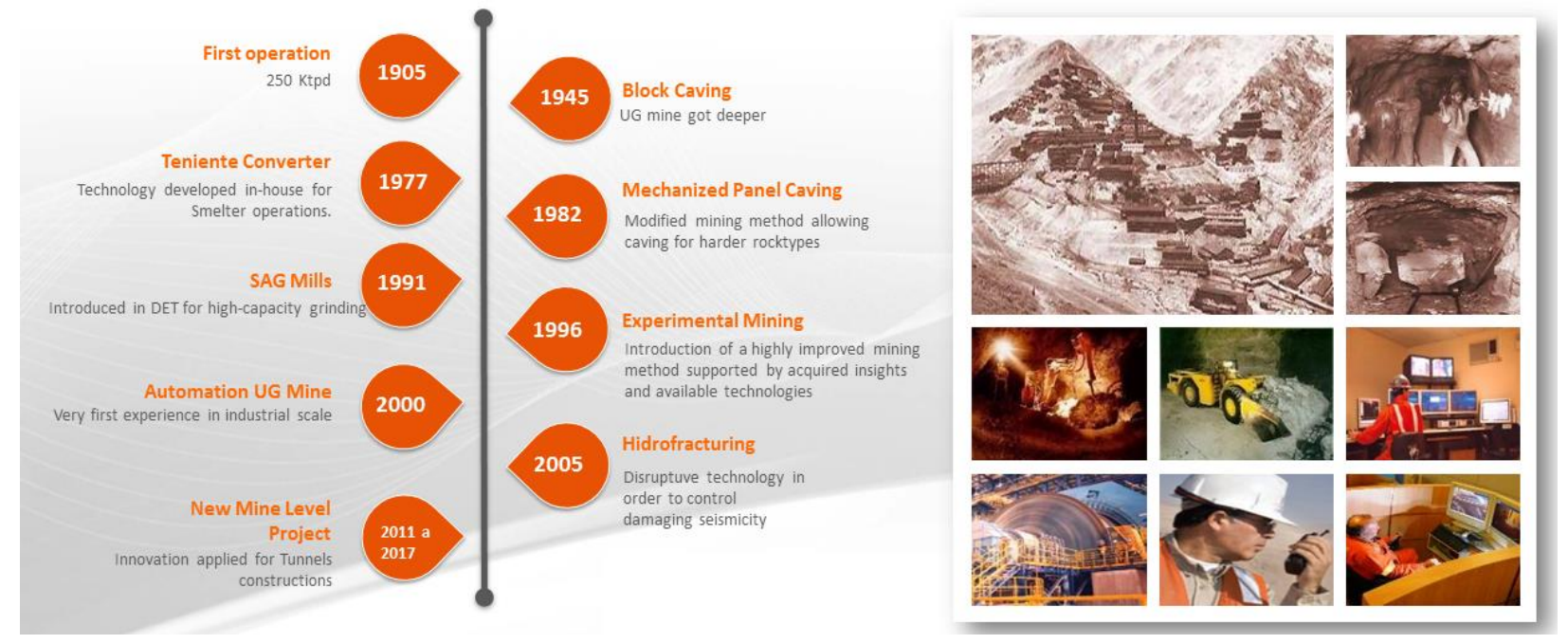

Figure 2 El Teniente's history of seeking and implementing innovative methods

In 2012, Codelco commenced a review of the status of autonomous technologies, with the objective of defining the technology closest to meeting the demands of the Chuquicamata Underground and New Mine Level structural projects. Thus, it was that in 2014, Finning Caterpillar was contracted to undertake a pilot test in the Esmeralda sector, to appraise the 'alpha' functions of semi-autonomous LHD operation. The objective of the test was to close the gaps recognised in the Pipa Norte experience of semi-autonomous operation, with respect to productivity, operational flexibility and the real capture of reduced exposure of personnel. A second phase of this project will consider, in 2019, similar test objectives, but in the operation of mining haul trucks.

At the same time, El Teniente has challenged itself in search of opening alternatives for exploitation in high-severity risk areas of operation. For example, in 2016, studies began to consider the exploitation of areas that had been abandoned up to that point related to the risk of mudrushes. After developing engineering studies with local universities, and visiting other mines in the world with similar conditions, mining tests were started in 2017 at Diablo Regimiento mine, using equipment operated remotely via joystick with a 'teleguidance' system and anti-collision mode. This technology, defined as multi-brand, presents important advantages, such as making the provider of the communication system independent of the LHD equipment manufacturer.

Today, El Teniente has established and is implementing a development strategy with clear objectives in terms of safety, productivity and quality of life in mining activities. El Teniente is collaborating with suppliers of autonomous operating systems that are adaptable to El Teniente operational conditions and requirements. Achievement of the integration of state-of-the-art communication and autonomous systems in the operation of the entire mobile mining fleet will underpin a safe and productive mining business for the near and medium future.

\subsection{El Teniente mine: cave mining variant - development, exploitation phases}

Copper mining in the El Teniente orebody, until the mid-1960s was located entirely within secondary mineralisation and extracted by block caving under relatively benign and manageable working conditions. A strategic drive to increase mine production at that time led to mining trials to develop a method that could successfully mine the competent and much stronger primary mineralisation, given the difficulty perceived in 
expanding mine production by extracting secondary mineralisation by block caving. In the course of those trials 'rock noise' was observed, a phenomenon not seen before in mining secondary ore. It consisted of a conspicuous effect associated with the fracture of the rock mass complemented by occasional and sudden rock ejection from the excavations (rockburst). At that time, analysis of the characteristics of the rock mass (geology and structures), in situ stresses and mining activities did not establish a relationship with the occurrence of rockbursts. In 1976, the design of the first mine sector, to be partly located in primary rock with $30 \%$ of the $160 \mathrm{~m}$ column height comprising primary mineralisation, was developed.

In 1982, the Teniente 4 Sur sector implemented a mechanised mining variant termed panel caving, whereby the cave front is continuously advanced, as opposed to the block cave variant in which a small mining area (or block) is undercut followed by a long period of draw. A series of rockbursts accompanied the mining of the Teniente 4 Sur sector. Subsequently, in 1989, Teniente Sub-6, a sector positioned entirely in primary mineralisation, commenced undercutting of the rock column. After only a few months of production, the sector was affected by intense seismicity causing significant damage to excavations and injury to the workforce, which necessitated the cessation of operations. Consequently, in 1994 a study phase called 'Experimental Mining' began in El Teniente mine (Rojas et al. 2000). As part of this development phase, a pre-undercut variant of panel caving was applied in the Esmeralda sector in 1997, which excavated the undercut ahead of the development of the production level, on the basis of mining in a benign stress environment. For various operational reasons, the application of pre-undercut mining, although considered successful in the early stages with respect to a benign mining environment, was not successful with respect to the loss of production area. Notwithstanding this, a number of lessons were learned with respect to how to manage large-scale caving operations located in difficult mining environments (Araneda \& Sougarret 2008).

In parallel with the development of the mining variant, hydraulic fracturing of the rock mass was introduced in the Diablo Regimiento sector, where it was demonstrated that the magnitude of cave mining-induced seismicity was considerably reduced, and subsequently confirmed in a recently completed mine-wide study of mining-induced seismicity (Mendecki et al. 2017) (Figure 3).

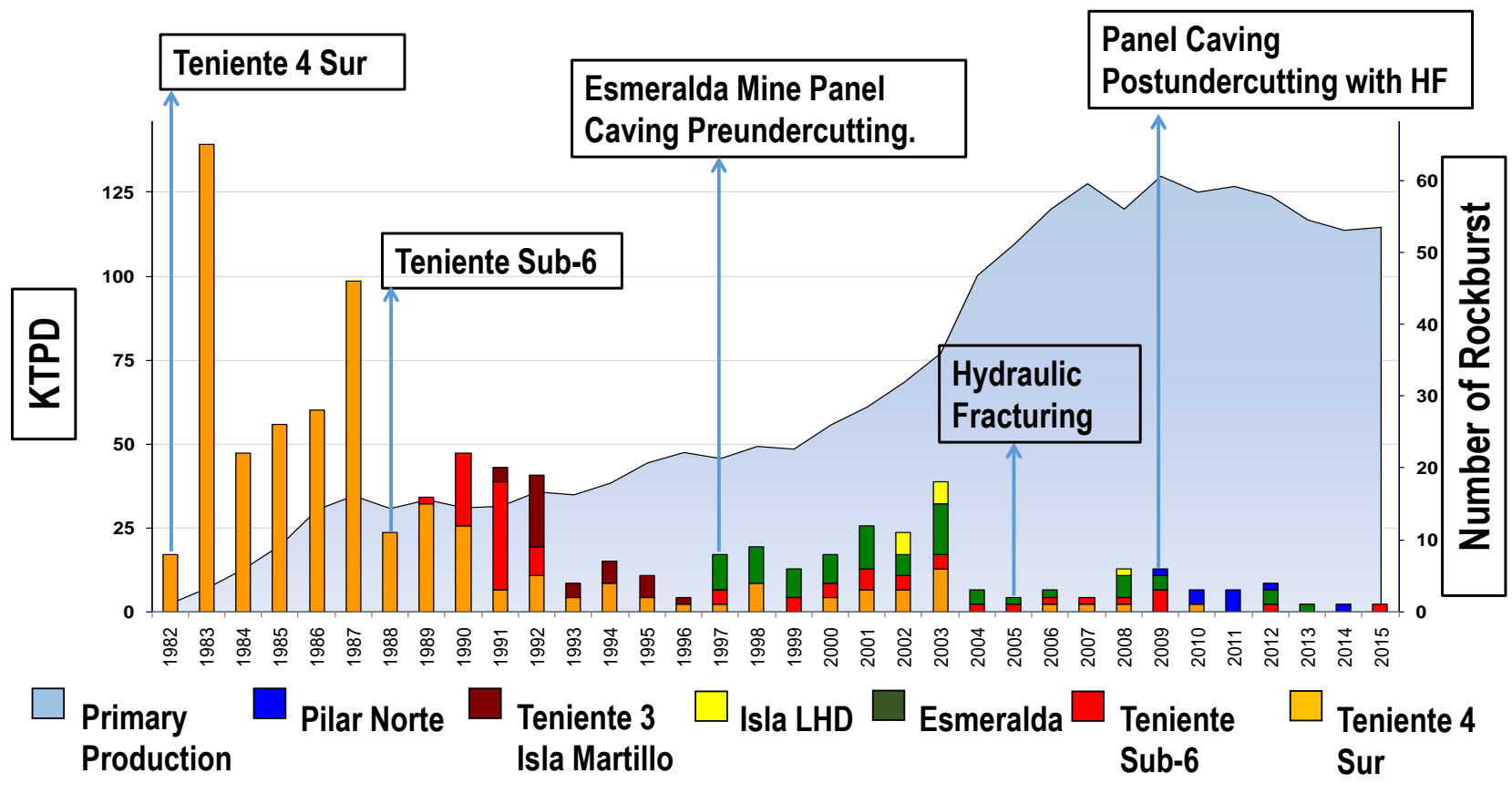

Figure 3 Evolution of production and rockbursts at El Teniente Mine

The application of the hydraulic fracturing technique was introduced at El Teniente in 2005. Hydraulic fracturing has been implemented widely within El Teniente since 2010, carried out from boreholes drilled vertically from the undercut level in the different sectors of the mine (Figure 4), and to date, more than 100 million cubic metres have been hydro-fractured. 


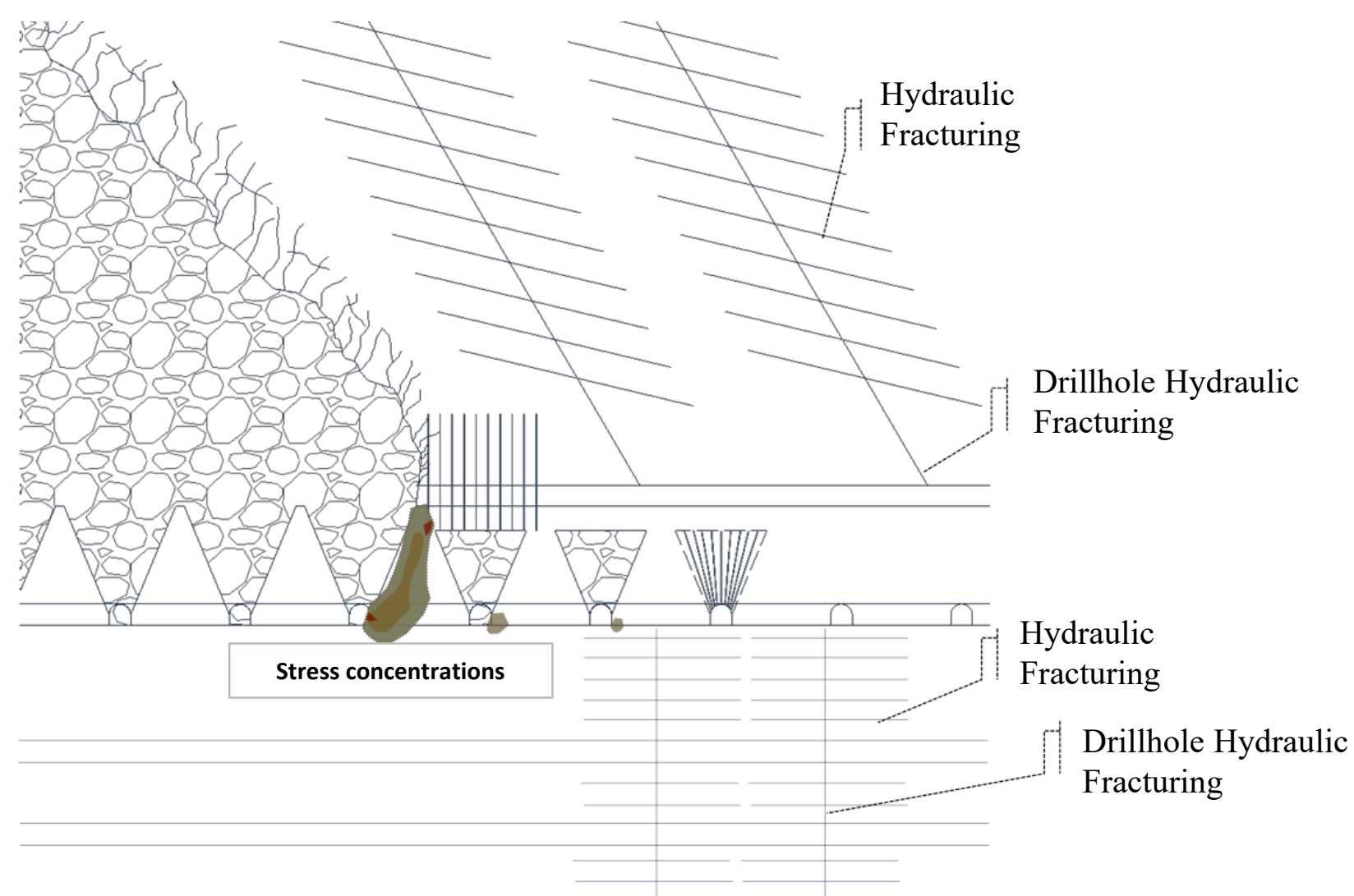

Figure 4 Panel caving post-undercutting with hydraulic fracturing (after Pardo et al. 2016)

In addition, hydraulic fracturing has been selectively applied under the production level enveloping geological features such as major faults and high stiffness intrusive lithologies.

As a consequence of the experimental mining research instigated in 1994, El Teniente has developed an understanding of the geomechanics mechanisms which impact the safety and productivity of cave mining, and how best to apply this knowledge (Landeros et al 2012; Ferguson 2015). The fruits of this work are presently being used to develop the future production sectors in El Teniente, at ever-increasing depths and mining environments subject to ever-increasing complexity (Pardo et al. 2016).

\subsection{Cadia East mine: mudrush hazard - exploitation phase}

Cadia East is currently experiencing fine fragmentation in drawpoints of the high cave columns implemented in the mine, and is seeking to address the uncertainty associated with the issue, given their previous experience in the adjacent Ridgeway Deeps mine. Mudrushes have affected caving operations worldwide, and continue to do so, and represent severe safety, productivity and economic challenges, causing multiple fatalities, serious disruption to business and sterilisation of reserves. Resolution of the problem over the short-term is essential for the cave mining industry, and requires appropriate resources.

Mudrush means a sudden uncontrolled outflow of mud, water or wet material from drawpoints, chutes, box fronts or any other underground workings (South African Mines Inspectorate 2011). Mudrush material is considered to behave like a liquid with a velocity greater than $3 \mathrm{~m} / \mathrm{sec}$. Mature caving operations are inherently susceptible to mudrushes, given their propensity to generate fines and accumulate water in the column of caved material, for example:

- Kimberley, South Africa.

- El Teniente, Chile.

- Andina, Chile. 
- Mt Lyell, Australia.

- Freeport, Indonesia.

- Ridgeway Deeps, Australia.

Recorded inrush events have been known to travel considerable distances in caving operations (Figure 5).

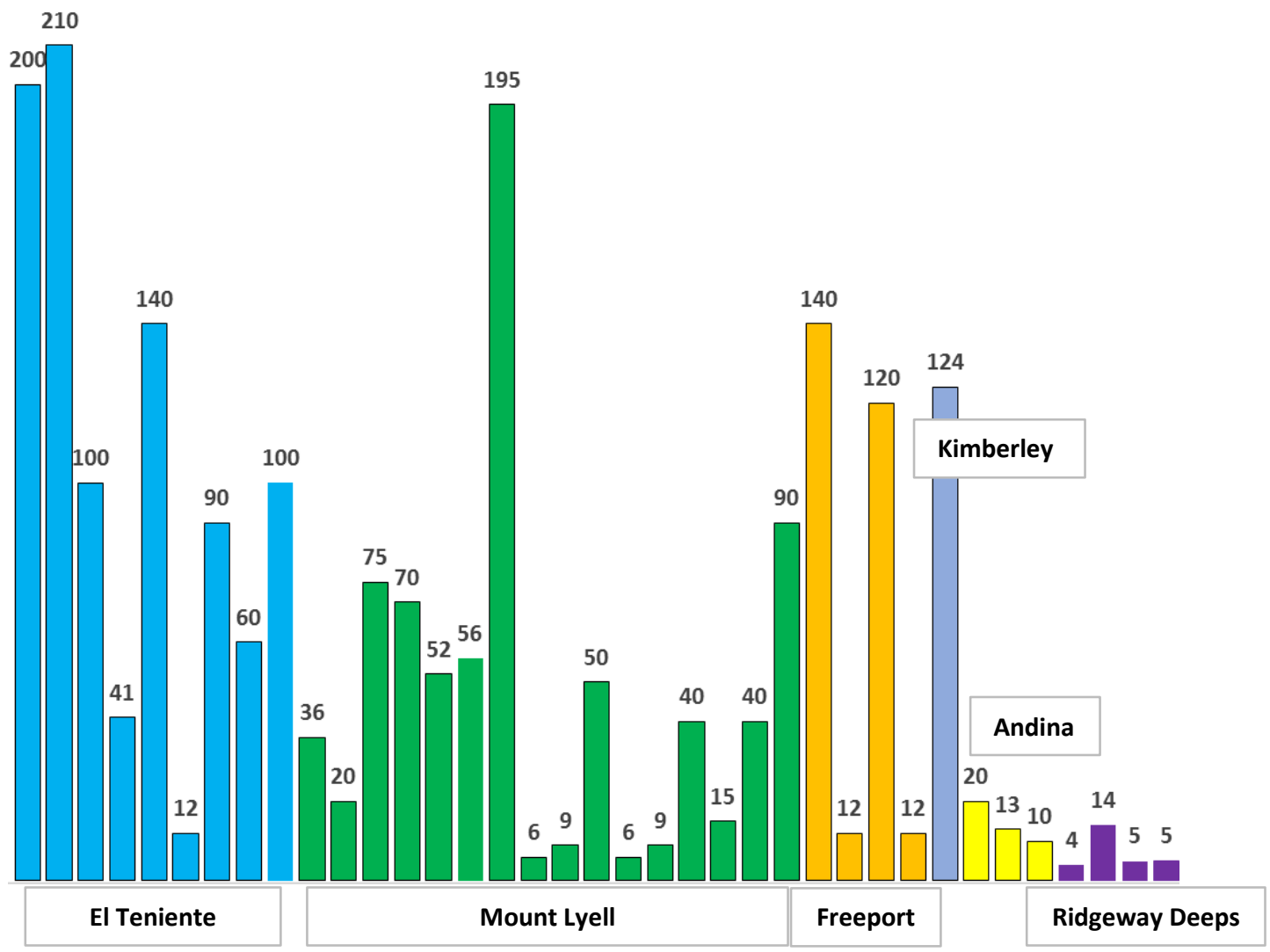

Figure 5 Mudrush - distances ( $\mathrm{m}$ ) travelled in block, panel and sublevel caving operations

Other geoscientific disciplines, for example the engineering of tailings dams that encompasses similar materials, enjoy well-established testing and well-understood conceptual models. A similar approach with respect to mudrushes has yet to be adopted by caving mines. As a consequence, technical support for managing mudrushes in caving mines tends to be qualitative rather than quantitative. An example of the qualitative approach is the drawpoint trigger action response plan (TARP) protocol developed by PT Freeport Indonesia (Table 2).

Table 2 Drawpoint classification by fragmentation and moisture content (after Widijanto et al. 2012)

\begin{tabular}{|c|c|c|c|}
\hline \multirow[b]{2}{*}{$\begin{array}{l}\text { Wetness/water } \\
\text { content }\end{array}$} & \multicolumn{3}{|c|}{ Material size $>5 \mathrm{~cm}(\mathrm{M})$} \\
\hline & $\begin{array}{l}M>70 \text { (dominated } \\
\text { by coarse grain) }\end{array}$ & $30 \%<M<70 \%$ & $\begin{array}{l}M<30 \% \text { (dominated } \\
\text { by fine grain) }\end{array}$ \\
\hline$<8.5 \%$ (dry) & $\mathrm{A} 1$ & B1 & $\mathrm{C} 1$ \\
\hline $8.5-11 \%$ moist & $\mathrm{A} 2$ & B2 & $\mathrm{C} 2$ \\
\hline$\geq 11 \%$ wet & $\mathrm{A} 3$ & B3 & $\mathrm{C} 3$ \\
\hline
\end{tabular}

Green $=$ any loader. Yellow $=$ any loader with supervision. Red = automated loader 
Implementation of a drawpoint TARP protocol in mines where mudrushes are likely is essential for the safety of personnel. Regrettably, qualitative protocols depend upon the perception of the workforce, and are thus likely to be ambiguous, which can compromise the integrity of an effective risk management process.

R\&D with respect to mudrush engineering needs to cover a number of aspects and parameters (Table 3 ).

Table 3 Suggested R\&D components to manage the mudrush hazard

\begin{tabular}{ll}
\hline Area/parameter & Description \\
\hline Testing & $\begin{array}{l}\text { Proper guidelines for testing are required in order to define index properties of } \\
\text { material such as grain size distribution, Atterberg limits, and void ratio, including } \\
\text { liquefaction susceptibility }\end{array}$ \\
Monitoring & $\begin{array}{l}\text { The TARP should be based on monitoring data, not observations only. Current } \\
\text { fragmentation tools used in caving require processing in the office and the } \\
\text { percentages of fines is an assumption for the analysis. } \\
\text { Inrush risk requires real-time monitoring. }\end{array}$ \\
Numerical & $\begin{array}{l}\text { Development of a numerical modelling tool that can combine fragmentation, flow } \\
\text { and water. }\end{array}$ \\
Scale models & $\begin{array}{l}\text { Scale models could be used to create a conceptual model and validate its } \\
\text { assumptions. The same model could be used to quantify the impact of the draw } \\
\text { strategy in mitigating the severity of mudrushes. }\end{array}$ \\
Bund design & $\begin{array}{l}\text { Some mines use bunds as a means of avoiding mudrushes from occurring. } \\
\text { However, there is not a clear standard for their construction. }\end{array}$ \\
Rock mass & $\begin{array}{l}\text { It seems reasonable to assume that different mineral compositions will have } \\
\text { different comminution resistances. } \\
\text { properties }\end{array}$ \\
Draw strategy & Establish clear guidelines with respect to managing the mudrush risk.
\end{tabular}

Probably the best strategy in caving is to reduce the exposure of personnel to drawpoints by:

- Ensuring that cave establishment activities (completion of the footprint) are finished well-behind the breakthrough.

- Once breakthrough to surface has occurred, activities such as loading, and removing hang-ups should only be performed by remote or unmanned equipment.

- Implement even draw strategies.

\subsection{Modelling the response of the rock mass to excavation}

Panel caving is in many ways a distinctive mining method. It calls for very high capital investment since all production development mining has to be completed in the pre-production phase. Opportunities to modify the design when production has started are minimal. Therefore, it is critical to achieve a good, if not a near-optimal design from the start of the project. The industry has developed an increasing reliance on numerical modelling to achieve such designs because it offers the possibility of making predictions. Although the reliability of these predictions is largely unknown, it is attractive to produce predictions which support the pre-conceived ideas of the designers.

Significant R\&D funding by the caving community in particular has been made during the last two decades to advance numerical models which have reached a very high level of sophistication. Investment has been substantial in applying these models extensively in projects at the scoping and feasibility stage, as well as in operating cave mines. Unfortunately, the investment and effort towards validating and calibrating these 
models has not been proportional to the development of the numerical codes and their applications to cave mining. In fact, it can be argued that no model has ever been validated or properly calibrated to cave mining.

Donigian (2007) defines validation and calibration of numerical models as follows:

- Validation: comparison of modelling results with numerical data independently derived from experiments and measurements in the field.

- Calibration: a test of a model with known input and output information that is used to adjust or estimate factors for which data are not available (errors occur in parameter measurements in the field and parameter adjustments).

Modellers aim at calibrating their models based on correlations between model results and scarce measurements, often in the periphery of the caving area, mainly in the mine infrastructure where access is possible, or from observation boreholes and surface subsidence. In the cave back, numerical model results are often compared against seismic data. However, seismic data produced by seismic monitoring systems in mines are model-dependent interpretations of the measured waveforms. Seismic systems only measure waveforms of velocity against time at a sensor's location. Indeed, the source location, magnitude of seismic events, source size and other parameters are post-processed interpretations based upon a geophysical model. Therefore, the industry generally correlates numerical modelling results with model dependent interpretation of data from seismic systems.

Furthermore, a seismic event is an indication of a brittle failure somewhere in a rock mass volume. Such failures may range in scale from micro-cracking to earthquake. The interpretation of seismicity in terms of the status of the rock mass in the context of a load-deformation response to caving is largely unknown (Cumming-Potvin \& Wesseloo 2014). Duplancic (2001) provided a conceptual model for cave propagation and this is universally applied as a framework to interpret seismic and non-seismic data, as well as the interpretation of numerical modelling results. As this model encapsulates the current 'expected' cave behaviour, it is consciously or subconsciously used to 'calibrate' numerical models in cave mining. It may assist in interpreting modelled seismic data, but most caves deviate from this simplified conceptual model. The presence of faults which may have not been modelled, for example, will significantly affect caving behaviour.

Essentially, based on Donigian's (2007) definition, numerical models have neither been validated nor properly calibrated because the failure mechanisms occurring within a cave column have never been observed, and there are very few opportunities to make measurements and verifications. A few point measurements from boreholes over an enormous volume of failing rock mass is the best that has been achieved to date in terms of observations and direct measurements.

Recent work towards achieving validation of numerical models for caving mines used a centrifuge as a physical model (Cumming-Potvin et al. 2016a, b; Cumming-Potvin 2018). This low-budget preliminary research work is in sharp contrast to the funds invested to date in developing and applying various numerical modelling codes, without proper validation and calibration. The same physical model can be potentially used to validate the modelling of seismic data and techniques such as active and passive tomography. At present, validation of numerical models is yet to generate much interest in the caving community.

We consider that the cave mining industry must turn its attention to validation and calibration of numerical models, if it is to continue to rely on them as a tool for design. Centrifuge modelling has shown excellent potential for validation of models. In terms of calibration, more R\&D is required to develop field measurements inside the cave. New generations of instruments such as smart markers and magnetic beacons have opened up new possibilities for measuring cave material flow, and this technology needs to be extended to provide direct measurements of rock mass failure (Elexon Mining 2018).

Another area where caving geomechanics research is required is the study of large seismic events and rockbursts. Considerable work has been done during the last three decades on this topic, but mainly in the context of open stope mining. Other than El Teniente mine, this problem is relatively new to cave mining but it is becoming increasingly critical to the industry, with more applications of very large caves at depth, and in stronger and stiffer rock masses such as the Cadia East mine. 
Fundamental differences exist between cave and open stope mining that will require consideration in the study of rockbursts and seismicity. Compared to open stoping, cave mining can fracture an extremely large volume of rock very rapidly when cave propagation is achieved. This may inhibit the capacity of relieving stored strain energy gradually and generate a more violent response, especially when pillars between existing caves are reduced.

Furthermore, as faults and shears are generally present within or in the surrounding cave area, cave progression may induce an increase in the shear stress or a reduction in the normal stress acting on faults/shears (de-clamping). This could trigger slips or mine-induced earthquakes. Classical seismology teaches us that the size of the slip dictates the magnitude of the seismic event. In cave mining, very large areas of faults can be de-clamped very rapidly. It is reasonable to think that the 'super caves' of the future will generate seismic events larger than those that have been experienced to date in open stope mining. The industry needs to pro-actively develop the science to mitigate this very severe risk. Hydraulic fracturing has been implemented by El Teniente engineers to mitigate this risk, who are at the forefront of designing and applying this very beneficial technique. Much work remains to be performed in order to better understand and, therefore, design future hydraulic fracturing applications.

\section{Conclusion}

It is concluded that:

1. There is a need for innovative progress in the cave mining industry, and more metals must be produced with greater safety and efficiency with the goals of reducing costs and meeting global demand.

2. Current industrial practice is simply inadequate with respect to rock mass characterisation, and operational and fundamental research in this area is warranted.

3. Research objectives need to focus on how best to resolve key project and operational problems and risks, as well as their impact on critical performance indices.

4. Without doubt, the best caving research over the last couple of decades has arguably been achieved by Codelco, who have maintained a very strong internal research group with practical advances made with respect to developing caving guidelines, ground support and rock mass preconditioning.

5. A shared informal network approach to cave mining R\&D, therefore, makes sense from both commercial and mining industry health and safety aspects, based upon a return to strong industry internal research groups.

6. Based upon Donigian's (2007) definition, numerical models have neither been validated nor properly calibrated because the failure mechanisms occurring within a cave column have never been observed, and there are very few opportunities to make measurements and verifications.

7. Accordingly, advances in numerical modelling are urgently needed if the industry is to pro-actively develop the science of mitigating the very severe risk of mining-induced seismicity, encompassing the response of the rock mass to excavation and how hydraulic fracturing modifies this response.

\section{Acknowledgement}

The authors are grateful for permission to publish this paper, given by Codelco and Newcrest Mining Limited, and acknowledge that the views expressed herein are those of the authors and do not necessarily represent corporate views. 


\section{References}

Araneda, O \& Sougarret, A 2008, 'Lessons learned in cave mining at the El Teniente mine over the period1997-2007', Proceedings of MassMin 2008, Luleå University of Technology, Luleå, pp. 43-52.

Cumming-Potvin, D 2018, An Extended Conceptual Model of Caving Mechanics, PhD thesis, The University of Western Australia.

Cumming-Potvin, D, Wesseloo, J, Jacobsz, SW \& Kearsley, EP 2016a, 'Fracture banding in caving mines', The Journal of the Southern African Institute of Mining and Metallurgy, vol. 118, no. 8, pp. 753-761.

Cumming-Potvin, D, Wesseloo, J, Jacobsz, SW \& Kearsley, E 2016b, 'Results from physical models of block caving', Proceedings of MassMin2016, The Australasian Institute of Mining and Metallurgy, Melbourne, pp. 329-340.

Cumming-Potvin, D \& Wesseloo, J 2014, 'Assessing the state of the rock mass in operating block caving mines: A review', in R Castro (ed.), Proceedings of the Third International Symposium on Block and Sublevel Caving, Universidad de Chile, Santiago, pp. 118-127.

Donigian, AS 2007, Watershed Model Calibration and Validation: Issues and Procedures, Aqua Terra Consultants, Mountain View.

Duplancic, P 2001, Characterisation of Caving Mechanisms Through Analysis of Stress and Seismicity, PhD thesis, The University of Western Australia.

Elexon Mining 2018, Wireless Ground Movement Monitoring, https://elexonmining.com

Ferguson, GA 2015, Evolution of a Design Methodology for Use in Cave Mines Developed in Challenging Geomechanics Environments, unpublished PhD thesis, The University of Leeds, Leeds.

Landeros, P, Cuello, D \& Rojas, E 2012, 'Cave-back management at Reservas Norte Mine, Codelco Chile, El Teniente Division', Proceedings of MassMin 2012, Canadian Institute of Mining, Metallurgy and Petroleum, Westmount.

Maxwell, SC, Rutledge, J, Jones, R \& Fehler, M 2010, 'Petroleum reservoir characterization using downhole microseismic monitoring', Geophysics, vol. 75, no. 5, pp. 75A129-75A137.

Mendecki, AJ \& Lötter, EC 2017, Elements of Seismic Hazard for El Teniente/NML Seismogenic Area, report, Institute of Mine Seismology, Hobart.

Pardo, C \& Rojas, E 2016, 'Selection of a mining method based on the experience of hydraulic fracture techniques at the El Teniente mine', Proceedings of MassMin 2016, The Australasian Institute of Mining and Metallurgy, Melbourne, pp. 97-103.

Potvin, Y \& Wesseloo, J 2013, 'Towards an understanding of dynamic demand on ground support', in Y Potvin \& B Brady (eds), Proceedings of the Seventh International Symposium on Ground Support in Mining and Underground Construction, Australian Centre for Geomechanics, Perth, pp. 287-304.

Rojas, E, Cavieres, P, Dunlop, R \& Gaete, S 2000, 'Control of induced seismicity at El Teninte mine, Codelco-Chile', in G Chitombo (ed.), Proceedings of MassMin 2000, The Australasian Institute of Mining and Metallurgy, Melbourne, pp. 775-781.

South African Mines Inspectorate 2011, Guideline for the Compilation of a Mandatory Code of Practice for the Design, Development/Construction, Safe Operation and Maintenance of Draw Points, Tipping Points, Rock Passes and Box Fronts, Department of Mineral Resources, Pretoria.

Tregelles, PG 1978, Strategy for Mining Research and Development in the United Kingdom (Coal Industry), presented at a Joint Meeting of The Institution of Mining Engineers and The Institution of Mining and Metallurgy held at the Europa Hotel, London, 27th January 1978.

Widijanto, E, Sunyoto, W, Wilson, AD, Yudanto, W \& Soebari, L 2012, 'Lessons learned in wet muck management in Ertsberg East Skarn System of PT Freeport Indonesia', Proceedings of MassMin 2012, Canadian Institute of Mining, Metallurgy and Petroleum, Westmount. 